\title{
Plant and Equipment Spending in 1969 and 1970
}

Plant AND EQUiPment SPENDING by American business is projected to rise by more than 10 percent in 1970, according to the first quarter survey of the Office of Business Economics and the Securities and Exchange Commission (OBE-SEC). While such a rise does not amount to a boom, it does appear surprisingly large in the face of stagnation in the growth of real gross national product, declining profits, sagging stock prices, low capacity utilization in manufacturing, repeal of the investment tax credit, and bond yields that were at record highs in late January and February when the survey was made.

If realized, these reported anticipations (plans reported by businesses but adjusted upwards to reflect systematic underestimations in the past) would amount to the seventh largest percentage increase in the twentythree years the survey has been conducted (behind 1951, 1956, the years 1964-66, and 1969). Although at the current rate of increase of the investment price deflator, about 4 percent of the rise would reflect price increases, the real growth would be substantially greater than that predicted for the economy as a whole. Coming on top of an 11.5 percent rise in 1969, the advance would carry business spending to a volume, measured as a proportion of predicted gross national product, that would place 1970 alongside the boom years of 1956 and 1957. 


\section{How Much?}

Will the anticipated rise take place? Evidence from other leading indicators clouds the view. Starting with data pointing to a smaller rise, net new orders for machinery and equipment for the six-month period September 1969 through February 1970 were only 6 percent higher than in the corresponding period a year earlier; for December through February the increase was only 2 percent above the corresponding year-earlier period. ${ }^{1}$ With the value of contracts for commercial and industrial construction included, orders and contracts together were about 8 percent above their year-earlier levels, for both the December-February and the SeptemberFebruary comparisons. On the exceptionally bullish side, new capital appropriations by the 1,000 largest manufacturing firms during the fourth quarter of 1969 exceeded those in the fourth quarter of 1968 by more than 13 percent; a comparison of the last halves of these two years shows a 16 percent gain. However, it should be noted that in times of tight money the share of investment carried out by the biggest corporations tends to be larger than usual, presumably because smaller firms feel the effect of capital rationing most strongly.

Some evidence may be gained from considering the revisions of the anticipations that have been measured several times. After adjustment by the Office of Business Economics, the survey taken in late October and November projected annual rates of $\$ 81.0$ billion for the first quarter of 1970 and $\$ 82.93$ billion for the second quarter. In the January-February survey the projections are scaled down to $\$ 80.0$ billion and $\$ 81.78$ billion, respectively. Furthermore, in the interval between the November-December and January-February surveys, reported plans for 1970 declined by about 1 percent.

It would certainly be dangerous to try to project these small cutbacks as a trend, and to say that current plans will not be realized because of further cutbacks. Nevertheless, the anticipations data should not be taken as revealed truth. While the forecasting record of the series is quite good, the average absolute error for the year-long projections made in January and February is 3.1 percent. Furthermore, the adjusted anticipations have been above the realizations for all of the past four years, by small amounts in

1. All monthly and quarterly figures referred to have been adjusted to eliminate seasonal influences. 
1966 and 1967, but by $\$ 2.9$ billion in 1968 and $\$ 2.2$ billion in 1969 . The errors in anticipations have tended to go in "runs"- -with substantial periods of overprediction followed by periods of underprediction.

I am not prepared to make a formal forecast for 1970, but the leading indicators cited above push me toward the conclusion that the 8 percent rise in plant and equipment spending forecast by the Council of Economic Advisers is in the right ball park. Nothing I have mentioned to this point gives any indication of why business spending should be rising at all. That more difficult question will be taken up later.

\section{Who Is Spending?}

More than a quarter of the $\$ 8$ billion rise indicated by the anticipations survey is accounted for by electric utilities, with large increases in longdistance lines, interconnections, and other transmission equipment. The $\$ 2.2$ billion rise planned by electric utilities constitutes a 20 percent boost, and, if realized, would signal the sixth consecutive year of exceptional increase for this industry.

In absolute terms, the next largest increase, $\$ 1.4$ billion, would occur in the communications industry. This represents a 17 percent rise for an industry that projected an advance of 15 percent for 1969 but actually ended up spending 22 percent more than in 1968.

The largest percentage increase is planned by the railroads-a half-billion dollar gain. This would be a 27 percent increase following a 28 percent rise in 1969. Purchases of super-size jets by the airlines account for most of the 16 percent rise in planned expenditures for the air transportation industry. Other industries projecting large percentage increases include electrical machinery, nonelectrical machinery, and stone, clay, and glass. The only published categories in which decreases are reported are the steel, transportation equipment, rubber, "other transportation," and gas utilities industries.

\section{How Can We Explain 1969?}

Although, as noted above, the planned increases for 1970 seem to be supported by other estimates, and although the larger rises in 1969 are already on record, there remains the problem of explaining why investment spending has been so strong in the face of a weakening economy. With the 
warning that these preliminary figures may be revised substantially before they become "final," this question must nevertheless be approached. Simple but popular models of investment spending based on either the "cash flow" or the "accelerator" view of investment are examined below and found to shed little light on the problem, but more sophisticated models also produce substantial errors.

Using quarterly data covering 1953-68, I have estimated the quantitative relationship between capital expenditures from the OBE-SEC survey (in current dollars) and lagged corporate cash flow (profits after taxes plus depreciation charges). The "best" results are achieved by making investment dependent on cash flow in the previous six quarters with nearly all of the weight in the previous four quarters. ${ }^{2}$ The standard error of estimate, $\$ 864$ million, is impressively small, but the errors go in runs: Once the equation gets off the track, it tends to produce errors of the same sign and nearly the same magnitude in succeeding periods. ${ }^{3}$

It seems clear that something important is missing from the model. When the equation is extrapolated into 1969 , even using the information contained in the residual for the fourth quarter of 1968, the predictions are very poor. As summarized in Table 1 , the errors rise to more than $\$ 5$ billion in the last half of 1969, and the percentage error for the whole year exceeds 5 percent. In view of the decline in after-tax profits during the third and fourth quarters of 1969 , which led to declines in cash flow, projecting this model ahead to 1970 would almost surely produce inferior results, barring a large (and at this point totally unforeseen) rebound in profits.

As a second simple model I have specified deflated plant and equipment expenditures to be a function of lagged real output (measured by the gross product of private nonfarm business). This may be thought of as a generalized accelerator model. ${ }^{4}$ As before, the fit in the sample period is very

2. An Almon distributed lag procedure was used and the best results were found by experimenting with the length of the lag.

3. The estimation procedure includes the assumption of first order correlation and thus the estimation is carried out essentially on first differences of the variables. The high serial correlation coefficient of 0.94 indicates the presence of extreme autocorrelation in the errors.

4. The Almon distributed lag procedure is used. The results are not at all sensitive to the number of lagged output terms included, but the best fit is achieved with thirteen. Once more the errors are highly autocorrelated, with the first order serial correlation coefficient again being 0.94 . 


\section{Table 1. Expenditures for Plant and Equipment, Actual, and Predicted Using Cash Flow and Accelerator Models, by Quarter, 1969}

Dollar amounts in billions, seasonally adjusted annual rate

\begin{tabular}{|c|c|c|c|c|}
\hline $\begin{array}{l}\text { Quarter } \\
\text { and year }\end{array}$ & Actual & Predicted & $\begin{array}{c}\text { Predicted } \\
\text { minus actual }\end{array}$ & $\begin{array}{l}\text { Percentage } \\
\text { error }\end{array}$ \\
\hline \multicolumn{5}{|c|}{ Cash flow model ${ }^{a}$} \\
\hline 1 & $\$ 72.53$ & $\$ 69.88$ & $\$-2.65$ & $-3.6 \%$ \\
\hline 2 & 73.94 & 71.13 & -2.81 & -3.8 \\
\hline 3 & 77.84 & 72.05 & -5.79 & -7.4 \\
\hline 4 & 77.84 & 72.80 & -5.04 & -6.5 \\
\hline Year & 75.54 & 71.46 & -4.07 & -5.4 \\
\hline \multicolumn{5}{|c|}{ Accelerator model ${ }^{\mathrm{b}}$} \\
\hline 1 & 60.38 & 58.78 & -1.60 & -2.6 \\
\hline 2 & 61.21 & 59.23 & -1.98 & -3.2 \\
\hline 3 & 63.44 & 59.55 & -3.89 & -6.1 \\
\hline 4 & 62.93 & 59.87 & -3.06 & -4.9 \\
\hline Year & 61.99 & 59.36 & -2.63 & -4.2 \\
\hline
\end{tabular}

Sources: Actual, Survey of Current Business, Vol. 50 (March 1970), pp. 11 and 19; predicted, author's estimates.

a. Current dollars.

b. 1958 dollars.

good, with a standard error of estimate of $\$ 921$ million. The results of extrapolation of this model into 1969 are also found in Table 1. The errors are large, exceeding $\$ 3$ billion in both the third and fourth quarters, with an average error of more than 4 percent. With real output declining in early 1970, this model would also not be expected to project a large rise in investment for this year.

Nor do more sophisticated models, which take more factors into account, hold the key. As an example, I present some results from a pair of equations explaining expenditures on producers' durable equipment, the largest component of nonresidential business fixed investment. This equation takes account of, among other things, the relative price of equipment, the corporate tax rate, accelerated depreciation, the investment tax credit, and capital costs as measured by both the yield on stocks and an approximation to the real interest rate. ${ }^{5}$ The two equations first predict orders for equipment and then predict expenditures based on orders. The fit during

5. The equation involves a rather complicated lag structure and possibly controversial specification of the variables. 
Table 2. Expenditures for Producers' Durable Equipment, Actual and Predicted, by Quarter, 1969

Dollar amounts in billions of 1958 dollars, seasonally adjusted annual rate

\begin{tabular}{ccccc}
\hline $\begin{array}{c}\text { Quarter } \\
\text { and year }\end{array}$ & Actual & Predicted & $\begin{array}{c}\text { Predicted } \\
\text { minus actual }\end{array}$ & $\begin{array}{c}\text { Percentage } \\
\text { error }\end{array}$ \\
\hline 1 & $\$ 55.5$ & $\$ 55.2$ & $\$-0.3$ & $-0.5 \%$ \\
2 & 57.7 & 55.8 & -1.9 & -3.3 \\
3 & 57.8 & 56.2 & -1.6 & -2.8 \\
4 & 58.6 & 56.0 & -2.6 & -4.4 \\
Year & 57.4 & 55.8 & -1.6 & -2.8 \\
\hline
\end{tabular}

Sources: Actual, Survey of Current Business, Vol. 50 (March 1970), p. 8; predicted, author's estimates.

the sample period is not quite as impressive as that of the other models, but there is much less serial correlation. The results of estimating the equations through 1968 and then extrapolating forward into 1969 may be found in Table 2. Again there is persistent underestimation, gradually growing worse. Because of the lag structure, very little of the effect of repeal of the investment tax credit shows up in 1969, but the model predicts a strong depressing effect in 1970 and 1971. This model, like the others, proves to be not very useful in explaining what happened in 1969 or what seems to be happening in 1970.

What other factors could be built in? Perhaps the current inflationary episode has radically changed the way in which businessmen form their expectations. This is something that is very difficult to measure. Perhaps wage increases deserve a more direct role than they have in the fancier model, where they enter only indirectly as an element inducing capitallabor substitution, that is, through the real interest rate variable. No allowance is made for the sort of expectations that might lead, for example, to hurried construction of a plant to avoid higher construction costs later on. There is no mechanism to allow for the possibility that expansion plans put off in 1967 or 1968 in hopes of lower interest rates could no longer be postponed. Perhaps capacity is more fully utilized than current measures indicate; better indices might be very useful. Perhaps disaggregation would reveal something that the aggregate analysis hides.

The search for ad hoc explanations could go on and on. But it will stop here for now. 


\section{Discussion}

Charles bischoff pointed out in summarizing his report that capacity utilization was not included as a variable in any of the equations he had studied. However, several participants noted that including measures of capacity utilization could not have helped to explain the large increase in investment in 1969, since the indices of operating rates were quite low.

Lawrence Klein said that disaggregating the investment by sectors helps to reveal a more understandable pattern. Much of the special strength of investment in 1969-70 is in the area of utilities and communications. Capacity in these industries had fallen behind the need and this investment represents a catching up. In manufacturing, however, investment is not out of line with equations based on past experience. Only in the commercial sector is investment surprisingly high, and it is probably being affected by the outlook for future costs and prices.

George Terborgh pointed out that 1970 is the sixth year of an investment boom, as measured by the capital expenditures of nonfinancial corporations relative to their gross corporate product and by the ratio of capital expenditures to internal funds. He commented: "The first four years of this boom can be rationalized fairly well by the enormous increase in private employment that occurred in that period. But 1969 and 1970 cannot be fully explained in this way. They probably reflect, in addition to the effect of growth in employment, the expectation of rapidly rising labor costs and attempts to avoid higher costs for equipment and construction in the future."

Along the same line, Alan Greenspan pointed out that long-term expectations of more rapid rises in wage rates increase the rate of return on replacement of existing facilities. There was general agreement that expectations of future wage increases enhance the incentives to invest currently, implying a substitution of capital for labor. Bischoff noted that this effect should have been picked up by the real rate of interest variable.

Paul Samuelson suggested that few businesses that had invested more than the equations said they "should" had reason to be sorry. Inflation has bailed out "wrong decisions." Daniel Brill commented that profits began to fall off late in 1969. This may make some businessmen sorry and lead to downward revisions of current plans. 